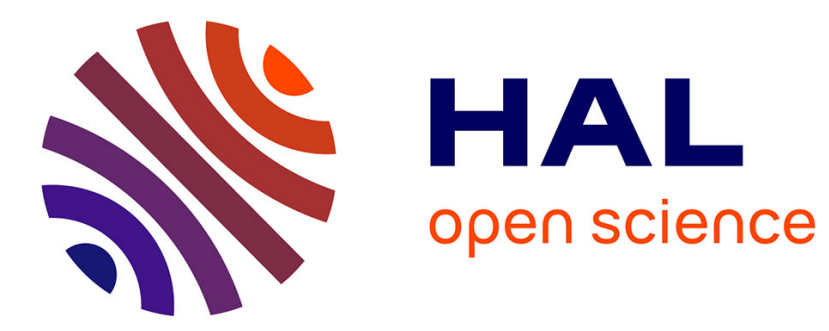

\title{
Deeper Insights into a Bioactive Glass Nanoparticle Synthesis Protocol To Control Its Morphology, Dispersibility, and Composition
}

Xavier Kesse, Charlotte Vichery, J.-M. Nedelec

\section{- To cite this version:}

Xavier Kesse, Charlotte Vichery, J.-M. Nedelec. Deeper Insights into a Bioactive Glass Nanoparticle Synthesis Protocol To Control Its Morphology, Dispersibility, and Composition. ACS Omega, 2019, 4 (3), pp.5768-5775. 10.1021/acsomega.8b03598 . hal-02078624

\section{HAL Id: hal-02078624 \\ https://hal.science/hal-02078624}

Submitted on 25 Mar 2019

HAL is a multi-disciplinary open access archive for the deposit and dissemination of scientific research documents, whether they are published or not. The documents may come from teaching and research institutions in France or abroad, or from public or private research centers.
L'archive ouverte pluridisciplinaire HAL, est destinée au dépôt et à la diffusion de documents scientifiques de niveau recherche, publiés ou non, émanant des établissements d'enseignement et de recherche français ou étrangers, des laboratoires publics ou privés. 


\title{
Deeper Insights into a Bioactive Glass Nanoparticle Synthesis Protocol To Control Its Morphology, Dispersibility, and Composition
}

\author{
Xavier Kesse, Charlotte Vichery,*(i) and Jean-Marie Nedelec ${ }^{(\bullet}$ \\ Université Clermont Auvergne, CNRS, SIGMA Clermont, ICCF, F-63000 Clermont-Ferrand, France \\ Supporting Information
}

\begin{abstract}
The aim of this study was to investigate the effect of three synthesis parameters on the morphology and composition of nanosized binary bioactive glass particles (nBGPs) obtained through a modified Stöber process. Syntheses were conducted by varying only one parameter at a time while keeping the other parameters constant. As already mentioned in the literature, the ammonium hydroxide volume conditioned the size of the nanoparticles. Nonagglomerated monodispersed spherical particles with a diameter between 70 and $452 \mathrm{~nm}$ were produced. The quantity of calcium nitrate and the moment it was introduced in the sol had a tremendous impact on the quantity of calcium inserted and on the particle morphology and aggregation state. High Ca-content particles were obtained when the calcium precursor addition time was 1

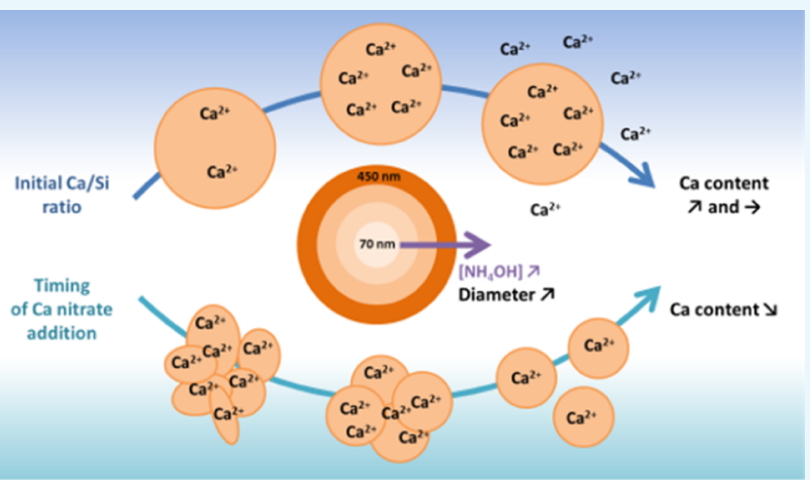
$\mathrm{h}$ or less after the beginning of the sol-gel reaction but at the cost of a strong aggregation. A better control on the morphology, polydispersity and dispersibility of the nBGPs was achieved when the $\mathrm{Ca}\left(\mathrm{NO}_{3}\right)_{2}$ addition time was increased up to $6 \mathrm{~h}$. However, a significant decrease of the quantity of $\mathrm{Ca}^{2+}$ inserted was also noticed. Using an intermediate $(3 \mathrm{~h})$ addition time, the quantity of calcium nitrate has been optimized to maximize the insertion of $\mathrm{Ca}^{2+}$ ions inside the silica particles. Finally, an optimum initial $\mathrm{Ca} / \mathrm{Si}$ atomic ratio of 2 , maximizing $\mathrm{Ca}$ insertion while limiting the salt quantity used, was found. It led to the synthesis of particles with a molar composition of $0.9 \mathrm{SiO}_{2}-0.1 \mathrm{CaO}$ without any side effect on the particle stability and morphological characteristics.
\end{abstract}

\section{INTRODUCTION}

It is has been established that bioactive glass particles (BGPs) can form a direct and strong chemical bond with bones when implanted in living tissues. ${ }^{1}$ In vitro studies conducted in Simulated Body Fluid (SBF) showed that this bonding ability is due to the formation of a hydroxyapatite (HAp) layer on the glass surface. ${ }^{2}$ In addition, while the HAp layer grows, the glass particles dissolve, leaving in the end, a completely new bone matrix without any residue of the starting material. Hence, they are one of the most promising biomaterials for bone tissue regeneration. ${ }^{2}$ In the 90 's, the advances in sol-gel research marked a new turning point in the elaboration of BGPs traditionally obtained by the melt-quenching route. ${ }^{3}$ This wet chemistry process leads to the formation of an inorganic silica network by mixing at room temperature the precursors, mostly alkoxides. This route leads to the synthesis of materials with a pore volume and a specific surface area higher (up to 2 orders of magnitude) than the melt-derived ones. Because of the ability to form a HAp layer being directly linked to the specific surface area, sol-gel BGPs account for a higher bioactivity as reported by Sepulveda et al. ${ }^{4}$ Moreover, for binary bioactive systems $\left(\mathrm{SiO}_{2}-\mathrm{CaO}\right)$, the compositional range to show a bioactive behavior is extended. BGPs with a $\mathrm{SiO}_{2}$ content up to $90 \%$ mol can be produced, whereas with the melt-quenching route, the $\mathrm{CaO}$ content has to be at least $50 \%$ mol. $^{5,6}$ In addition, the sol-gel method is extremely versatile, as the physical properties such as particle size and morphology can be controlled by playing on the process itself. ${ }^{7} \mathrm{~A}$ lot of research is currently ongoing to reduce the size of the BGPs to obtain increased specific surface area and thus increased surface reactivity, leading to faster glass dissolution, hence improving bioactivity properties. Also, it has been pointed out that nanosized bioactive glass particles (nBGPs) could promote better human marrow mesenchymal cell attachment and proliferation as compared to micron-sized bioactive glass particles. ${ }^{8}$ Therefore, an improvement of BG osteogenic properties can be expected at the nanoscale. Despite their great potential for bone regeneration, they are not yet used because of their novelty, leaving the autograft as the gold standard procedure for load-bearing bones. Considering that the natural bones can be described as composites composed of collagen fibrils and HAp nanocrystals, there is a great interest for the elaboration of mimetic nanocomposite scaffolds with nBGPs dispersed in a polymer. ${ }^{9-11}$ However, the aggregation

Received: December 21, 2018

Accepted: January 31, 2019

Published: March 25, 2019 

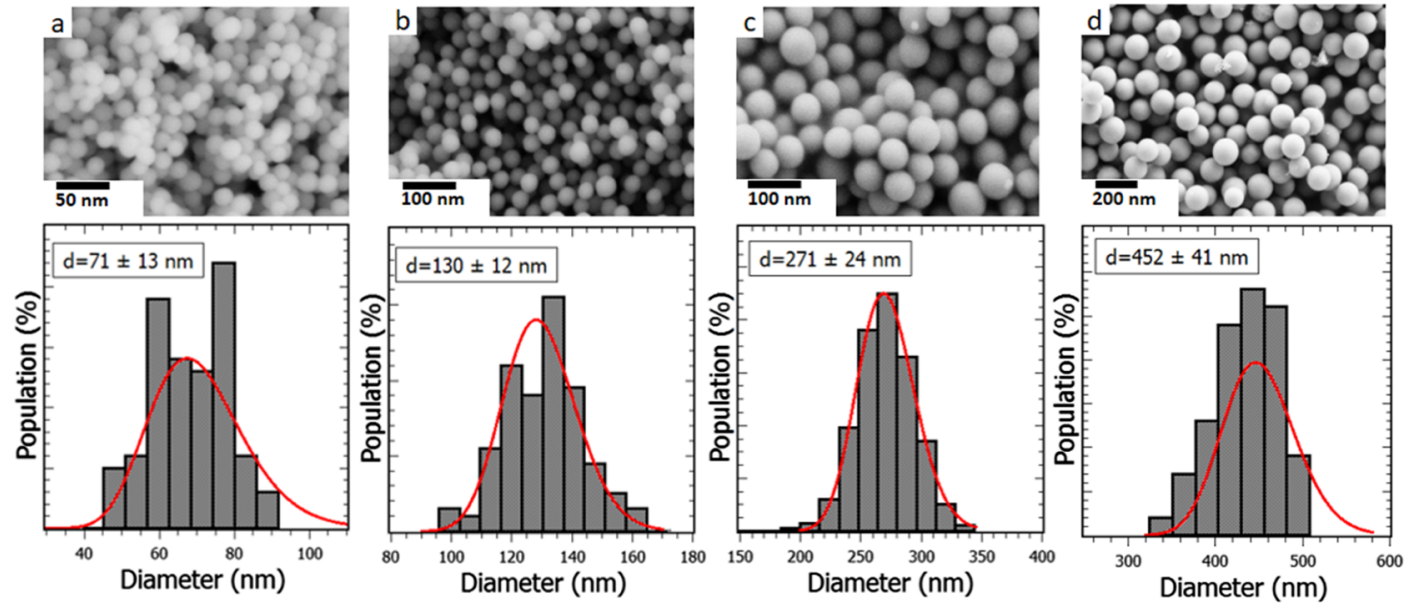

Figure 1. SEM images and size distribution histograms of nBGPs obtained with different $\mathrm{NH}_{4} \mathrm{OH}$ concentrations: (a) 0.14 , (b) 0.21 , (c) 0.33 , and (d) $0.57 \mathrm{M}$.

of $\mathrm{nBGPs}$ in the polymer matrix reduces the interaction between particles and the polymer structure, limiting the toughness of the nanocomposite materials as compared to natural bones. ${ }^{12}$ It is thus of tremendous importance to synthesize BGPs which are both in the nanoscale and nonagglomerated. A modified Stöber process allows obtaining such well-dispersed nanoparticles. ${ }^{13}$ It involves the hydrolysis and condensation of a silicon alkoxide precursor (usually tetraethyl orthosilicate, TEOS) in an alkaline solution to obtain in the first step $\mathrm{SiO}_{2}$ nanoparticles. The synthesis has to be performed under strong basic conditions (ammonium hydroxide, $\mathrm{NH}_{4} \mathrm{OH}$ ) to lead to particles and not to a lowreticulated silica network. Also, being at high $\mathrm{pH}$ induces a negative charge at the surface of silica particles, which repel one another by electrostatic repulsion. In the second step, a calcium salt is added (often calcium nitrate), resulting in the adsorption of $\mathrm{Ca}^{2+}$ ions onto the surface of the pristine silica particles. Calcium is only incorporated in the silica network after a $400{ }^{\circ} \mathrm{C}$ thermal treatment (diffusion), performed after a washing step. $\mathrm{Ca}^{2+}$ ions act as network modifiers, reducing the glass network connectivity, thus providing the bioactivity property. ${ }^{14}$ The calcium addition step must be carefully controlled to avoid side effects such as irregular morphology, ${ }^{15}$ inhomogeneity in size, ${ }^{16}$ and aggregation. ${ }^{17}$ Beyond the importance of calcium ions in the elaboration of bioactive systems, numerous studies investigated their effect on biological responses. Maeno et al. ${ }^{18}$ figured out that osteoblast proliferation and differentiation are enhanced in the presence of calcium ions, as well as extra cellular matrix mineralization. Marie $^{19}$ showed that extracellular calcium ion concentration controls osteoblast differentiation and proliferation via the activation of Ca-sensing receptors in the osteoblast cells. Furthermore, in vitro studies carried out by Pereira et al. ${ }^{20}$ showed that a high amount of calcium ions incorporated in BGPs induced a fast nucleation of HAp crystals. Thus, a fine control of the nBGP synthesis protocol with high calcium content is critical to further improve the bioactivity and biological properties of nanocomposite scaffolds. It has been reported that the aggregation state, size, size dispersity, and morphology of nBGPs with high calcium content $(20 \% \mathrm{~mol}$ $\mathrm{CaO}$ ) were optimized when the initial $\mathrm{Ca} / \mathrm{Si}$ molar ratio was of $1.3 .^{21}$ Also, Greasley et al. ${ }^{22}$ found out that this same ratio was optimal for a maximal insertion of $\mathrm{Ca}^{2+}$ ions $(9 \% \mathrm{~mol} \mathrm{CaO})$ in monodispersed nBGPs. More recently, Zheng et al. ${ }^{23}$ reported that the timing of calcium nitrate addition affected greatly the morphology, aggregation state, and composition of nBGPs. Greasley et al. ${ }^{22}$ performed nBGP synthesis slightly differently from the modified Stöber process described previously, with a centrifugation step after the silica particle formation and no washing steps after $\mathrm{Ca}^{2+}$ addition and before thermal treatment. In the following, we present a one-pot strategy to synthesize nBGPs and evaluate the impact of calcium nitrate addition time and $\mathrm{Ca} / \mathrm{Si}$ initial molar ratio on the nBGP morphology, size, size dispersity, and calcium content. Also, to modulate the specific surface area of the particles, ammonium hydroxide concentration has been varied because it was recognized in the literature as the major parameter impacting the size of silica particles in the Stöber process. ${ }^{22}$

\section{RESULTS AND DISCUSSION}

2.1. Variation of $\mathrm{NH}_{4} \mathrm{OH}$ Concentration. The impact of ammonium hydroxide concentration was investigated, keeping all the other synthesis parameters constant. The initial $\mathrm{Ca} / \mathrm{Si}$ ratio was 0.2 , and calcium nitrate was added after $24 \mathrm{~h}$ and the particles were recovered and washed $3 \mathrm{~h}$ later. A range of $\mathrm{NH}_{4} \mathrm{OH}$ volume $V$ from 0.75 to $3 \mathrm{~mL}$ was used. This corresponds to concentrations from 0.14 to $0.57 \mathrm{M}$ if one considers only ethanol as a solvent (water being a reactant). Figure 1 shows the scanning electron microscopy (SEM) images of the nBGPs elaborated by this modified Stöber process, all presenting a spherical morphology and being nonagglomerated. The size histograms, fitted with log-normal distribution functions, give a precise insight on the mean sizes and size dispersity. One can see that the nBGP mean diameter increases significantly as the concentration of ammonium hydroxide increases from 71 to $452 \mathrm{~nm}$ but that the size dispersity stays always low (between 18 and 6\%). Another indicator of the size dispersity is the polydispersity index (PDI) measured by dynamic light scattering (DLS). It is defined as: PDI $=(\sigma / D)^{2}$ where $\sigma$ is the standard deviation of the particle diameter distribution and $D$ is the mean particle diameter. As it can be seen in Table 1, the PDI values are between 0 and 0.1 , a range which characterizes highly monodispersed systems. ${ }^{24}$ The mean diameters obtained by DLS are slightly higher than the one previously presented for SEM measurements (from 87 to $485 \mathrm{~nm}$ ). This is perfectly consistent as DLS measures 
Table 1. Mean size (D), size dispersity, and specific surface area obtained by different methods for nBGPs synthesized with $\mathrm{NH}_{4} \mathrm{OH}$ concentrations in a range of $0.14-0.57 \mathrm{M}$

\begin{tabular}{|c|c|c|c|c|c|c|}
\hline \multirow[b]{2}{*}{ samples } & \multicolumn{2}{|c|}{ TEM } & \multicolumn{2}{|c|}{ DLS } & \multicolumn{2}{|c|}{$\begin{array}{l}\text { specific } \\
\text { surface } \\
\text { area } \\
\left(\mathrm{m}^{2} / \mathrm{g}\right)\end{array}$} \\
\hline & $D(\mathrm{~nm})$ & $\begin{array}{c}\text { size } \\
\text { dispersity } \\
(\%)\end{array}$ & $D(\mathrm{~nm})$ & PDI & $S_{\mathrm{BET}}$ & $S_{\mathrm{SEM}}$ \\
\hline$C=0.14 \mathrm{M}$ & $71 \pm 1$ & 18 & 87 & 0.1 & 45 & 39 \\
\hline$C=0.21 \mathrm{M}$ & $130 \pm 12$ & 9 & 145 & 0.042 & 21 & 21 \\
\hline$C=0.33 \mathrm{M}$ & $271 \pm 24$ & 9 & 276 & 0.084 & 11 & 10 \\
\hline$C=0.57 \mathrm{M}$ & $452 \pm 41$ & 9 & 485 & 0.035 & 7 & 6 \\
\hline
\end{tabular}

hydrodynamic diameters (particle diameter plus the electric double layer and the hydration shell). This size evolution versus ammonia concentration can be explained by the synthesis mechanism. It is well-known that under Stöber conditions, TEOS hydrolysis and condensation lead to the formation of primary silica particles which then aggregate and form secondary spherical particles. Then, Ostwald ripening induces a homogenization of the particle size through the dissolution of the smallest particles used to feed the bigger ones. $^{25}$ In addition, because of the high $\mathrm{pH}$ value induced by the presence of $\mathrm{NH}_{4} \mathrm{OH}$ (above the isoelectric point of silicic acid), the silica particles newly formed remain well-dispersed and are very stable, thanks to their negative surface charge. ${ }^{26}$ Therefore, increasing the ammonium hydroxide concentration above a critical value promotes the formation of large primary particles, resulting in the formation of larger, well-separated, and monodispersed silica particles with a negative surface charge as evidenced by the zeta potential values (see Table 2 ).

Table 2. Zeta Potential Values of nBGPs Obtained with Different $\mathrm{NH}_{4} \mathrm{OH}$ Concentrations

\begin{tabular}{cc}
\hline $\mathrm{NH}_{4} \mathrm{OH}$ concentration $(\mathrm{M})$ & zeta potential $(\mathrm{mV})$ \\
0.14 & $-14 \pm 4$ \\
0.21 & $-18 \pm 4$ \\
0.33 & $-20 \pm 5$ \\
0.57 & $-14 \pm 4$
\end{tabular}

The specific surface area of the particles was assessed by nitrogen sorption $\left(S_{\mathrm{BET}}\right)$. This parameter is known to impact the dissolution rate of bioactive glasses and thus their bioactivity because it characterizes directly the glass active surface which can interact with the surrounding environment (physiological media). ${ }^{27}$ The adsorption-desorption isotherms of the particles are of type III (see Figure S1 in the Supporting Information), characteristic of nonporous materials according to the IUPAC classification. The BrunauerEmmett-Teller (BET) surface area decreases from 45 to 7 $\mathrm{m}^{2} / \mathrm{g}$ as the particle size increases (see Table 1 ). These values are higher than those of melt-derived bioglass $45 \mathrm{~S} 5$ microparticles $\left(0.15-2.7 \mathrm{~m}^{2} / \mathrm{g}\right)^{4}$ and are consistent with other studies reported on sol-gel-derived bioactive glass nanoparticles. ${ }^{28,29}$ Using the size histograms obtained from SEM micrographs, the theoretical specific surface area $\left(S_{\text {SEM }}\right)$ of the particles was calculated (see the Supporting Information for calculation details). For the calculations, we assumed a density of $2.2 \mathrm{~g} / \mathrm{cm}^{3}$. This value is slightly higher than the density of Stöber silica particles, ${ }^{30}$ as bioactive glasses synthesized are dense and nonporous and contain calcium, which is heavier than silicon. One can notice that the $S_{\mathrm{SEM}}$ and $S_{\mathrm{BET}}$ values are quite similar (see Table 1), proving that particles are not aggregated. It has been reported that the immobilization of $\mathrm{Ca}^{2+}$ ions onto the surface of the silica particles changed their surface chemistry, resulting in particle aggregation. ${ }^{31}$ Here, 24 $\mathrm{h}$ after the beginning of the sol-gel process, the particles might have been very stable, and thus, the impact of $\mathrm{Ca}^{2+}$ addition in the media on aggregation is rather small. Decreasing the $\mathrm{NH}_{4} \mathrm{OH}$ concentration below $0.14 \mathrm{M}$ led to agglomerated particles. The sizes obtained here are in accordance with the results of Greasley et al., ${ }^{22}$ even though their synthesis protocol differed after the silica particle formation step, underlining the fact that the particle size is defined during this first step, no matter the way $\mathrm{Ca}^{2+}$ ions are then inserted in the silica matrix. After the washing steps, only the $\mathrm{Ca}^{2+}$ ions that are ionically bonded with the $\mathrm{OH}$ species covering the particle surface still remain and then diffuse in the silica network via a thermal treatment at $650{ }^{\circ} \mathrm{C}$. As already mentioned in the literature, such a high temperature is not mandatory for ion diffusion ${ }^{14}$ but is necessary to remove the remaining nitrate ions at the particle surface. Figure 2 shows the X-ray diffraction (XRD)

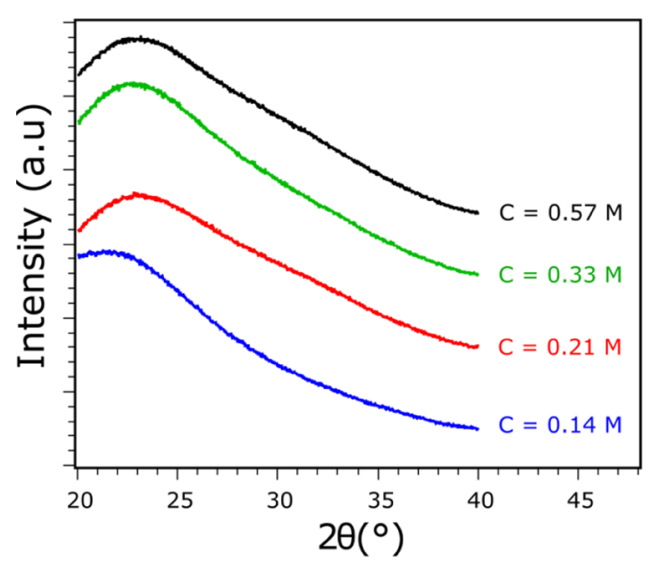

Figure 2. XRD patterns of nBGPs obtained with different $\mathrm{NH}_{4} \mathrm{OH}$ concentrations.

patterns of the nBGPs synthesized with different ammonium hydroxide concentrations. As it can be seen, no diffraction peaks were observed, confirming the amorphous nature of the nBGPs. ${ }^{32}$ One important result here is that it is possible to obtain bioactive glass nanoparticles as small as $70 \mathrm{~nm}$, with a low size dispersity and being nonaggregated with the modified Stöber process described in this study. In summary, we showed that ammonium hydroxide concentration has a great influence on the size of the bioactive glass nanoparticles. Indeed, increasing slightly its concentration results in a significant increase of the nBGP size, while a homogeneous spherical shape and a narrow size distribution are maintained. However, its concentration has to be maintained over a certain value to avoid the decrease of the double layer thickness of silica particles, which can promote aggregation. ${ }^{33}$

2.2. Variation of the Calcium Salt Addition Time. The impact of calcium nitrate addition time was investigated, keeping all the other synthesis parameters constant. The $\mathrm{NH}_{4} \mathrm{OH}$ concentration was fixed at $0.21 \mathrm{M}$ and the $\mathrm{Ca} / \mathrm{Si}$ ratio at 0.2 . $\mathrm{CaNO}_{3}$ addition was performed between $\mathrm{H}=30 \mathrm{~min}$ and $6 \mathrm{~h}$ after the beginning of the sol-gel reaction. All the obtained nBGPs are purely amorphous (see XRD patterns, 

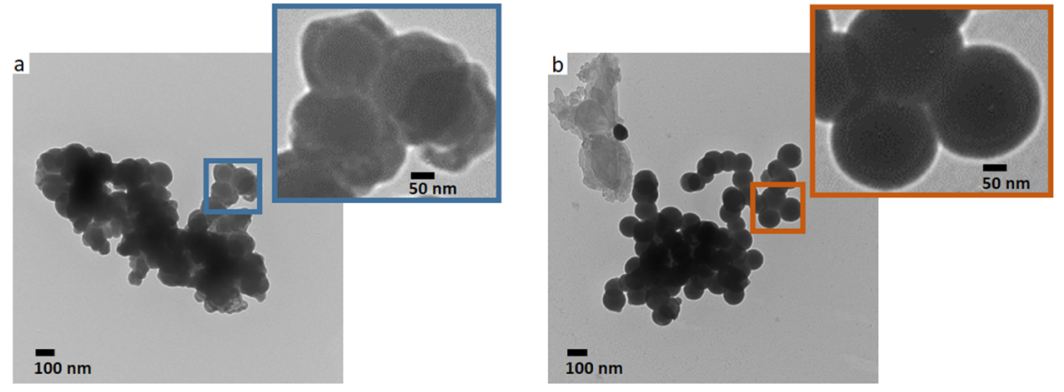

Figure 3. TEM images of (a) $\mathrm{nBGP}+30 \mathrm{~min}$ and (b) $\mathrm{nBGP}+1 \mathrm{~h}$.
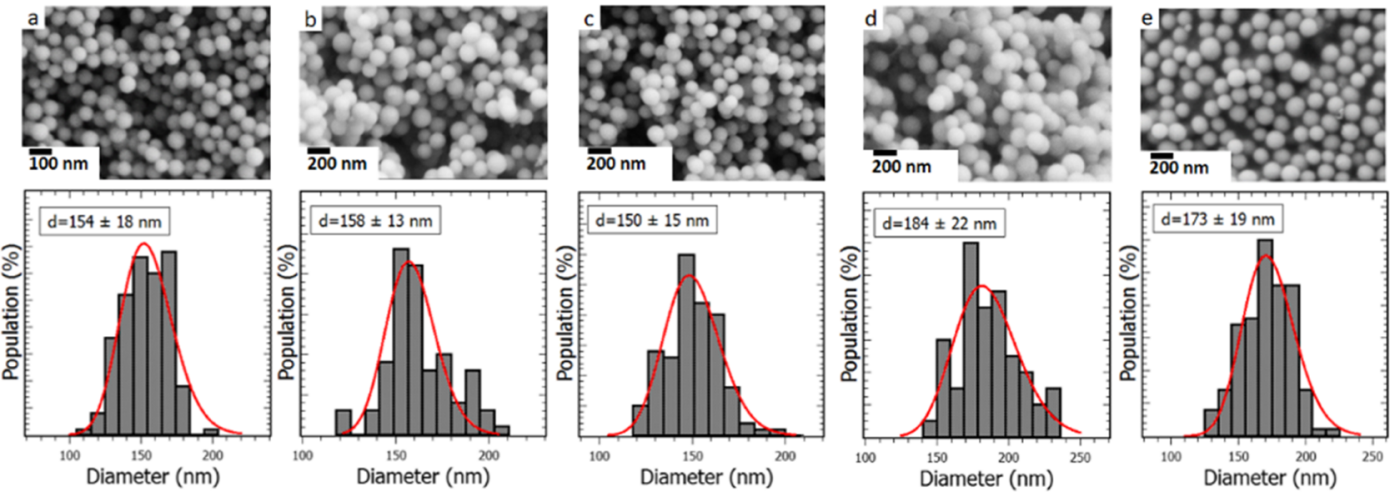

Figure 4. SEM images and size distribution histograms of (a) nBGP $+2 h$, (b) nBGP +3 h, (c) nBGP $+4 h,(d) n B G P+5 h$, and (e) nBGP +6 h.

Figure S2 in the Supporting Information). The transmission electron microscopy (TEM) images of the nBGPs obtained at $H=30 \mathrm{~min}(\mathrm{nBGP}+30 \mathrm{~min})$ and $H=1 \mathrm{~h}(\mathrm{nBGP}+1 \mathrm{~h})$ are shown in Figure 3. It can be seen that $\mathrm{nBGP}+30$ min particles are strongly aggregated and present an irregular morphology. On the contrary, $\mathrm{nBGP}+1 \mathrm{~h}$ particles exhibit a spherical morphology with a rather homogeneous size $(\sim 150 \mathrm{~nm})$, but they are still aggregated. The Figure 4 shows the SEM images of $n B G P+2 h, n B G P+3 h, n B G P+4 h, n B G P+5 h$, and $\mathrm{nBGP}+6 \mathrm{~h}$ particles. All of them are nonaggregated and exhibit a spherical morphology. The mean diameter and the size distribution evaluated by a log-normal function fit of the histograms are, respectively, $154 \pm 18,158 \pm 13,150 \pm 15$, $184 \pm 22$, and $173 \pm 19 \mathrm{~nm}$. One can notice that the bioactive nanoparticles are monodispersed in size (standard deviation of about $11 \%$ ) and that there is no significant difference between the particle diameters. It is well-known that the addition of an electrolyte in the solution during a sol-gel synthesis can impact the final structure of nBGPs because it impacts the colloidal stability of the pristine silica particles. ${ }^{33}$ Thirty minutes after the TEOS hydrolysis/condensation process, silica particles are not fully formed and are very reactive because of their small size. When the calcium salt is added, the overall electrostatic interaction is strongly attractive and the $\mathrm{Ca}^{2+}$ ions act as cross-linkers between the silica particles, hence destabilizing the particle dispersion. The nBGP $+30 \mathrm{~min}$ particles (see inset Figure 3a) are thus highly clustered with irregular morphology. This result is in good agreement with the work of Zheng et al. ${ }^{23}$ In the case of nBGP $+1 \mathrm{~h}$, the silica particles are a bit less reactive than the former ones. As a consequence, attractive electrostatic interactions are less effective and nBGPs are only moderately aggregated (see the necking parts in the inset Figure $3 \mathrm{~b}$ ) with a uniform spherical morphology. Over $1 \mathrm{~h}$, the colloidal stability is high enough for not being impacted anymore by the attractive electrostatic interactions induced by the addition of the calcium salt. The corresponding nBGPs are then nonaggregated and exhibit a spherical morphology with a uniform size distribution. In summary, the variation of the calcium salt addition time does not have a significant impact on the nBGP size but strongly influence their shape and aggregation state. An early addition of the calcium salt in the reaction media irreversibly destabilizes the colloidal suspension of silica particles because of the strong electrostatic interactions, resulting in their aggregation. The addition of the calcium salt thus have to be performed at least $2 \mathrm{~h}$ after the beginning of the sol-gel reaction. In the study of $\mathrm{Zheng}$ et al., ${ }^{23}$ this threshold time was at $30 \mathrm{~min}$. The difference with the present study could be explained by the different synthesis conditions used, such as a larger initial $\mathrm{Ca} / \mathrm{Si}$ ratio (0.614) and a larger $\mathrm{NH}_{4} \mathrm{OH}$ concentration $\left(1 \mathrm{~mol} \cdot \mathrm{L}^{-1}\right)$.

The composition of the particles synthesized with different calcium salt addition times $H$ has been investigated using energy dispersive X-ray spectroscopy (EDXS) to unravel its influence over the quantity of calcium effectively inserted in the silica matrix. The results are presented in Figure 5. When added early in the reaction system, at $H=30 \mathrm{~min}$ and $1 \mathrm{~h}$, respectively, 100 and $90 \%$ of the amount of calcium initially in the media has been incorporated. At $H=2 \mathrm{~h}$ and $H=3 \mathrm{~h}$, a decrease of this quantity is noticed ( $37 \%$ incorporation) and a significant drop can be seen at $H=4,5$, and $6 \mathrm{~h}$ (down to about $16 \%$ incorporation). This kind of deviation between the nominal and actual nBGP composition has already been reported and is for a part, a consequence of the washing step which removes the soluble calcium salt in the pore liquor (condensation byproducts), resulting in a lower amount of calcium nitrate deposited onto the surface of silica particles during the drying step. ${ }^{29}$ However, washings are mandatory 


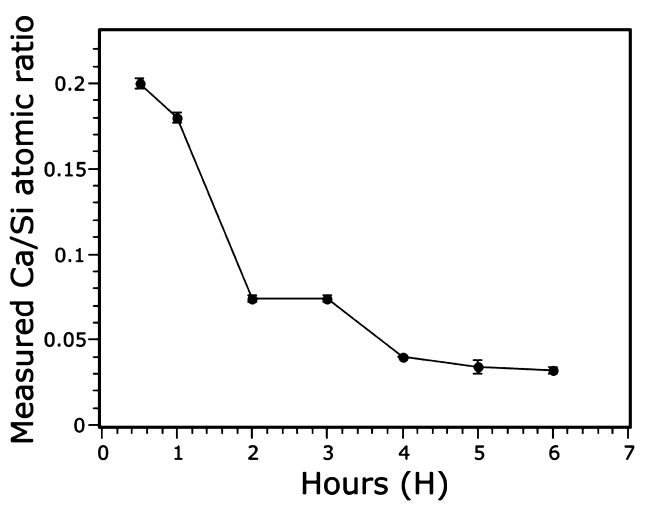

Figure 5. Evolution of measured $\mathrm{Ca} / \mathrm{Si}$ atomic ratio vs the precursor addition time $H$ for an initial $\mathrm{Ca} / \mathrm{Si}$ ratio of 0.2 .

because of the remaining unreacted precursors in the reaction media which could still react and form impurities or aggregate the particles. ${ }^{21}$ Nevertheless, this is not the main factor impacting the nBGP composition. The reactivity of the silica particles is closely related to its surface which is covered by silanol groups. ${ }^{26}$ The $\mathrm{pH}$ of the solution being higher than the isoelectric point of silicic acid $(\mathrm{pH}=2.2)$, the silanol groups are deprotonated, resulting in a negative surface charge as already mentioned. It is thus obvious that the number of silanol groups available at the silica particle surface when the calcium salt is added will strongly influence the composition of the synthesized nBGPs. At $H=30 \mathrm{~min}$ and $H=1 \mathrm{~h}$, hydrolysis and condensation still being ongoing, a maximum of these active sites might be available to create strong attractive electrostatic interactions with $\mathrm{Ca}^{2+}$ ions. Therefore, all (or almost all) the calcium is adsorbed onto the particle surface, resulting in a high quantity of $\mathrm{Ca}^{2+}$ ions inserted in the silica network after washing and calcination procedures. In the course of the sol-gel reaction, the negative charge density at the particle surface probably decreases because of the Ostwald ripening process, leading to the formation of larger silica particles. Hence, fewer active sites remain available to interact with the $\mathrm{Ca}^{2+}$ ions, resulting in a significant gap between the nominal and the actual composition of the nBGPs, as observed for the samples obtained at $H=2,3,4,5$, and $6 \mathrm{~h}$. These results are in perfect agreement with the ones of Zheng et al., ${ }^{23}$ who pointed out for the first time that the calcium salt addition time had a significant impact on the actual composition of the nBGPs. In their study, the initial $\mathrm{Ca} / \mathrm{Si}$ ratio was 0.614 and the resulting $\mathrm{Ca} / \mathrm{Si}$ ratio in the synthesized nBGPs was 0.1 (16\% insertion) for a $\mathrm{Ca}^{2+}$ addition time of $30 \mathrm{~min}$ and 0.03 (5\% insertion) for $1 \mathrm{~h}$ after the beginning of the sol-gel reaction. With the idea of maximizing the calcium content, Kozon et al. $^{34}$ and El-Rashidy et al. ${ }^{35}$ also synthesized monodispersed nBGPs with a modified Stöber method using a calcium nitrate addition time of $H=30 \mathrm{~min}$. The initial $\mathrm{Ca} / \mathrm{Si}$ ratios were, respectively, of 0.4 and 1 , leading to final $\mathrm{Ca} / \mathrm{Si}$ ratios within the particles of 0.03 (7.5\% insertion) and 0.07 (7\% insertion). The amount of calcium inserted in the particles in the former three studies was thus much lower than the ones presented here ( 0.2 and 0.18 for $H=30 \mathrm{~min}$ and $1 \mathrm{~h}$, respectively). It might be explained by their use of a larger concentration of $\mathrm{NH}_{4} \mathrm{OH}\left(1 \mathrm{~mol} \cdot \mathrm{L}^{-1}\right)$, which resulted in the synthesis of larger particles (about $400 \mathrm{~nm}$ ). It is interesting to mention that one could tailor the synthesis protocol depending on the application foreseen for the particles. If the particles are to be used as cement (e.g., mixed with blood to make a paste that would be pressed into bone defects), the fact that the particles are aggregated is not necessarily a drawback. In that case, an early addition of calcium will permit to obtain a highly bioactive material, thanks to the high calcium content. On the contrary, if well-dispersed nBGPs with uniform spherical morphology and a narrow size distribution are required, for example, to disperse them in a polymer matrix to obtain a nanocomposite material or to disperse them in an injectable preparation which would polymerize at body temperature and fill bone defects, nBGPs such as nBGP $+2 \mathrm{~h}$ or $\mathrm{nBGP}+3 \mathrm{~h}$ should be used.

2.3. Variation of the Initial $\mathrm{Ca} / \mathrm{Si}$ Ratio. In the previous section, we reported that spherical and nonagglomerated nBGPs with a narrow size distribution and a fair amount of calcium incorporated in the silica network could be achieved by adding the calcium salt in the reactive media 2 or $3 \mathrm{~h}$ after the beginning of the sol-gel reaction. Another parameter, the initial atomic ratio between $\mathrm{Ca}$ and $\mathrm{Si}$, could also have an impact, so it was investigated while keeping all the other synthesis parameter constant. The $\mathrm{NH}_{4} \mathrm{OH}$ volume was fixed at $1.12 \mathrm{~mL}(C=0.21 \mathrm{M})$ and the $\mathrm{CaNO}_{3}$ addition was performed $3 \mathrm{~h}$ after the beginning of the reaction. The initial $\mathrm{Ca} / \mathrm{Si}$ ratio was varied between 0.2 and 3.5. All the obtained nBGPs are purely amorphous (see the XRD patterns, Figure S2 in the Supporting Information). The obtained particles are all nonagglomerated as shown in the SEM images in Figure 6 and present a mean diameter around $180 \mathrm{~nm}$ with a standard deviation of about $10 \%$. The amount of calcium salt added in
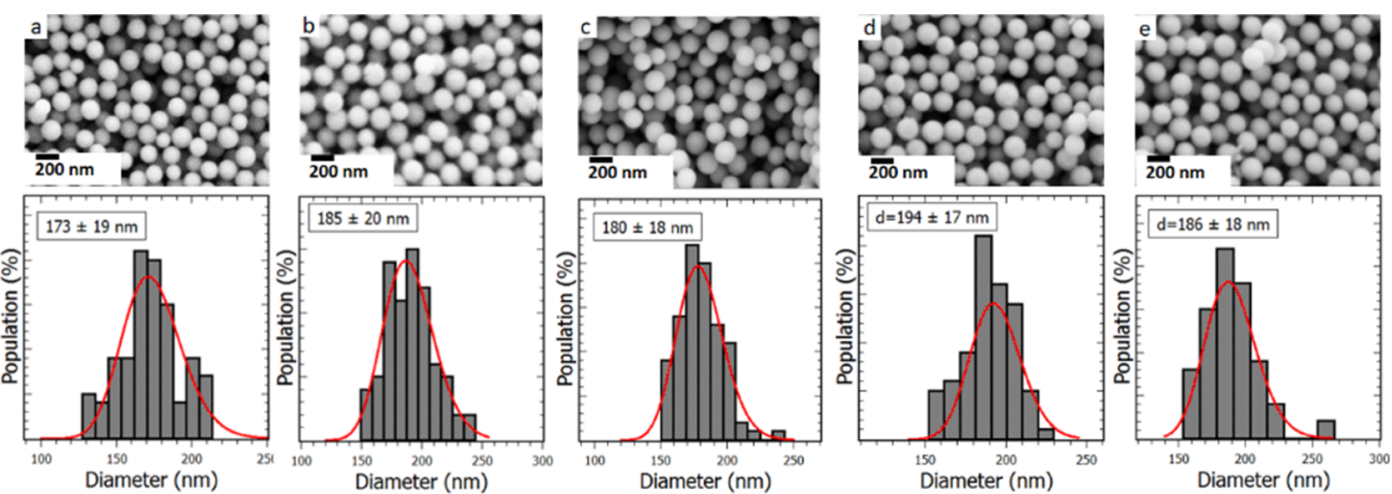

Figure 6. SEM images and size distribution histograms of nBGPs synthesized with different Ca/Si initial atomic ratios: (a) 0.75 , (b) 1.3, (c) 2, (d) 2.6, and (e) 3.5 . 
the reaction media thus had no impact on the colloidal stability of the particles, nor on their size and size dispersity. EDXS shows that the amount of calcium present in the nBGPs increases with the initial $\mathrm{Ca} / \mathrm{Si}$ ratio (see Figure 7). A

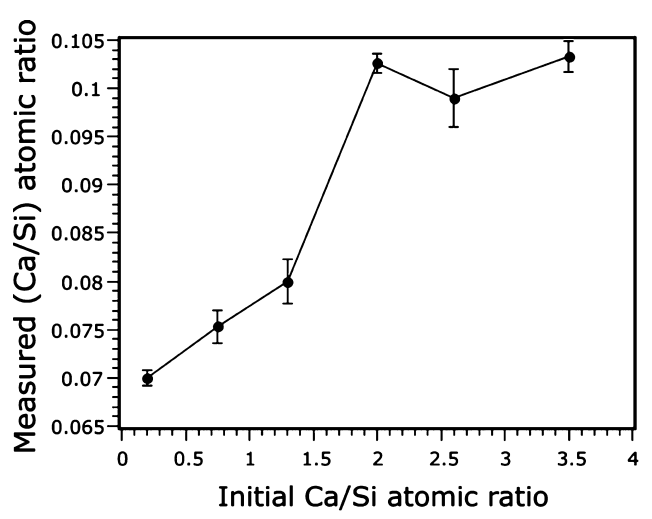

Figure 7. Evolution of measured $\mathrm{Ca} / \mathrm{Si}$ atomic ratio vs initial $\mathrm{Ca} / \mathrm{Si}$ atomic ratio.

saturation is reached at $\mathrm{Ca} / \mathrm{Si}=2$ with an effective $\mathrm{Ca} / \mathrm{Si}$ ratio of about 0.1 , which is higher than the optimal ratio value of 1.3 reported by Greasley et al. ${ }^{22}$ This saturation can be explained by the limited number of available site for $\mathrm{Ca}^{2+}$ ions to adsorb onto the particle surface. No further increase can happen due to the washing steps which remove nonadsorbed ions. However, it is important to notice that for an initial $\mathrm{Ca} / \mathrm{Si}$ ratio of 2 , only $5 \%$ of the $\mathrm{Ca}^{2+}$ ions are incorporated in the silica particles, which is not cost effective. Despite the smaller size of the particles studied by Greasley et al. ${ }^{22}$ (about $100 \mathrm{~nm}$ ) and thus their higher specific surface area, the quantity of calcium in the final nBGPs was not higher than the one we presented here. Playing on both the addition time and the initial quantity of calcium salt is thus of tremendous importance for one to optimize the calcium content in the synthetic nBGPs.

\section{CONCLUSIONS}

A one-pot-modified Stöber route was used to elaborate monodispersed nBGPs $\left(\mathrm{SiO}_{2}-\mathrm{CaO}\right)$. The influence of ammonium hydroxide concentration, calcium nitrate addition time $(H)$, and initial $\mathrm{Ca} / \mathrm{Si}$ atomic ratio upon the morphology, mean size, size dispersity, aggregation state, and composition of the nanoparticles has been investigated. The results showed that increasing the ammonium hydroxide concentration induced an increase of the mean bioactive glass nanoparticle diameter, while the timing of calcium salt addition (for $H \geq 2$ h) in the media and its quantity had no significant impact on its size. All particles were monodispersed in size and nonagglomerated, except for syntheses where calcium was added $1 \mathrm{~h}$ or less after the beginning of the sol-gel reaction $(H$ $\leq 1 \mathrm{~h}$ ). Regarding the composition of the nanoparticles, the results showed that the timing of calcium salt addition and the initial $\mathrm{Ca} / \mathrm{Si}$ ratio had a tremendous impact. For syntheses with $H \leq 1 \mathrm{~h}$, despite their strong agglomeration, the particles showed a high $\mathrm{Ca}$ content. However, for $H>1 \mathrm{~h}$, the quantity of $\mathrm{Ca}^{2+}$ ions inserted in the silica matrix decreased significantly. Also, it was found out that the initial $\mathrm{Ca} / \mathrm{Si}$ ratio had a significant impact on the final composition of particles. The amount of calcium inserted increased when increasing the initial $\mathrm{Ca} / \mathrm{Si}$ atomic ratio from 0.2 to 2 and then reached a plateau. On the light of the results obtained in this systematic study, it is now clearer and easier to understand the effect of the main synthesis parameters on the morphology and composition of bioactive glass nanoparticles obtained through a modified Stöber protocol. Future studies will focus on the bioactivity and the evaluation of the cytocompatibility of those nanomaterials to assess their possible benefits for bone tissue regeneration.

\section{MATERIALS AND METHODS}

4.1. Materials. TEOS (99\%), ammonium hydroxide solution $(28.0-30 \%)$, and calcium nitrate tetrahydrate (Ca$\left.\left(\mathrm{NO}_{3}\right)_{2} \cdot 4 \mathrm{H}_{2} \mathrm{O}\right)$ were purchased from Sigma-Aldrich. Absolute ethanol (99.5\%) was obtained from VWR Chemicals. All reagents were used as received without any further purification.

4.2. Synthesis. The bioactive glass nanoparticles were obtained following a modified Stöber route. Three parameters, (i) ammonium hydroxide concentration, (ii) the moment of addition, and (iii) the quantity of calcium nitrate, were varied while keeping all the other parameters constant to unravel their impact on the size and morphology of the BGPs and on the quantity of calcium inserted in the silica network. Briefly, two solutions were prepared separately at room temperature. The solution 1 was obtained by rapidly pouring $2.34 \mathrm{~mL}$ of TEOS in $20 \mathrm{~mL}$ of absolute ethanol and the solution 2 by mixing 11.7 $\mathrm{mL}$ of deionized water, $17.5 \mathrm{~mL}$ of absolute ethanol, and a concentration $\mathrm{C}$ of ammonium hydroxide ranging from 0.14 to $0.57 \mathrm{M}(V=0.75-3 \mathrm{~mL})$. After keeping these solutions under mechanical stirring for $30 \mathrm{~min}$, the solution 1 was dropped in the solution 2 and left to mix for a certain time $H$. After $H$ hours, a certain quantity of calcium nitrate dissolved in $1 \mathrm{~mL}$ of water, corresponding to a $\mathrm{Ca} / \mathrm{Si}$ ratio ranging between 0.75 and 3.5, was added to the resulting turbid solution and left under stirring for $(24-H)$ hours. The white suspension was collected by centrifugation $(6297 \mathrm{~g} / 20 \mathrm{~min})$ and washed with ethanol and water to remove nonreacted reagents. The obtained white solid was dried overnight at $60{ }^{\circ} \mathrm{C}$ and then heat-treated at $650{ }^{\circ} \mathrm{C}$ for $3 \mathrm{~h}$ to remove the remaining nitrate ions and to allow the incorporation of calcium into the amorphous silica network.

4.3. Characterization. The size and size distribution of nBGPs were investigated by TEM using a Hitachi H-7650 microscope operating at $80 \mathrm{kV}$. Micrographs were obtained by using a Hamamatsu camera placed in a side position. For TEM observation, the powders were dispersed in deionized water and sonicated for $10 \mathrm{~min}$. Then, $10 \mu \mathrm{L}$ of the suspension was deposited on carbon-formvar copper grids and left for drying overnight at room temperature. The morphology of the particles was also investigated by field emission SEM using a Zeiss Supra 55VP microscope operating at $3 \mathrm{kV}$, with a working distance in a range of $4.9-5.3 \mathrm{~nm}$. The particles were deposited on a conductive carbon tape (no metallization necessary). The particle size distribution was determined by the measurement of the diameter of more than 200 particles from TEM/SEM micrographs using the ImageJ processing software. The mean diameter and the size dispersity were obtained by fitting the size histograms with a log-normal distribution function. Chemical composition has been determined by EDXS in the scanning electron microscope using an X-MAX $80^{\mathrm{N}}$ spectrometer silicon drift detector (Oxford Instruments) coupled to the Oxford Instruments Aztec Advanced software. For EDXS measurements, the samples were pressed into pellets and deposited on a carbon 
film (no metallization). The experimental $\mathrm{Ca} / \mathrm{Si}$ ratios were calculated by dividing the measured atomic percentage of $\mathrm{Ca}$ measured by the measured atomic percentage of Si. Error bars on $\mathrm{Ca} / \mathrm{Si}$ values are calculated as: $\Delta(\mathrm{Ca} / \mathrm{Si})=\mathrm{Ca} / \mathrm{Si} \times$ $[(\Delta \mathrm{Ca} / \mathrm{Ca})+(\Delta \mathrm{Si} / \mathrm{Si})]$ where $\Delta \mathrm{Ca}$ and $\Delta \mathrm{Si}$ are the standard deviation of $\mathrm{Ca}$ and $\mathrm{Si}$ atomic percentages in three measurements. A calibration was performed by measuring the $\mathrm{Ca}$ and $\mathrm{Si}$ content of different ceramic powders of known $\mathrm{Si}$ and $\mathrm{Ca}$ concentrations. DLS and zeta potential measurement were performed using a Zetasizer Nano apparatus (Nano-ZS, Malvern Instruments). The powders were suspended in deionized water and sonicated for $10 \mathrm{~min}$ before the measurements. Powder XRD patterns were recorded using a D2 phaser (Bruker) diffractometer equipped with a $\mathrm{Cu} \mathrm{K} \alpha$ anode, in the range $2 \theta=20^{\circ}-40^{\circ}$ and with a step size of $0.016^{\circ}$. The specific surface area of nanoparticles was assessed by nitrogen sorption measurements conducted on a sorptometer (Micromeritics TriStar II Plus). Before the analysis, the samples were degassed under vacuum overnight at $150{ }^{\circ} \mathrm{C}$. The surface specific area was calculated using the $\mathrm{BET}$ equation on the adsorption branch.

\section{ASSOCIATED CONTENT}

\section{S Supporting Information}

The Supporting Information is available free of charge on the ACS Publications website at DOI: 10.1021/acsomega.8b03598.

Details of the calculation for the SEM-derived specific surface area values; $\mathrm{N}_{2}$ adsorption-desorption isotherms of nBGPs obtained at different $\mathrm{NH}_{4} \mathrm{OH}$ concentrations; and XRD patterns of nBGPs obtained for different calcium salt addition times and for different initial $\mathrm{Ca} / \mathrm{Si}$ atomic ratios $(\mathrm{PDF})$

\section{AUTHOR INFORMATION}

\section{Corresponding Author}

*E-mail: charlotte.vichery@sigma-clermont.fr. Phone: +33 473405479.

\section{ORCID}

Charlotte Vichery: 0000-0003-2455-0704

Jean-Marie Nedelec: 0000-0002-8243-6849

\section{Notes}

The authors declare no competing financial interest.

\section{ACKNOWLEDGMENTS}

The operation "AAP 'Nouveau Chercheur'-Nanoparticules bioactives et magnétiques pour le traitement de cancer et la régénération de tissus osseux" is cofunded by the European Union as part of the Fonds Européen de DÉveloppement Régional (FEDER) and by the Conseil Regional AuvergneRhône-Alpes. We also wish to thank Christelle Blavignac and Anne-Marie Gelinaud from CICS and 2MATech for technical assistance (TEM and SEM measurements).

\section{REFERENCES}

(1) Hench, L. L.; Splinter, R. J.; Allen, W. C.; Greenlee, T. K. Bonding mechanisms at the interface of ceramic prosthetic materials. J. Biomed. Mater. Res. 1971, 5, 117-141.

(2) Hench, L. L. The story of Bioglass. J. Mater. Sci. Mater. Med. 2006, 17, 967-978.
(3) Li, R.; Clark, A. E.; Hench, L. L. An Investigation of Bioactive Glass Powders by Sol-Gel Processing. J. Appl. Biomater. 1991, 2, 231239.

(4) Sepulveda, P.; Jones, J. R.; Hench, L. L. Characterization of meltderived $45 \mathrm{~S} 5$ and sol-gel-derived $58 \mathrm{~S}$ bioactive glasses. J. Biomed. Mater. Res. 2001, 58, 734-740.

(5) Martínez, A.; Izquierdo-Barba, I.; Vallet-Regí, M. Bioactivity of a $\mathrm{CaO}-\mathrm{SiO} 2 \mathrm{Binary}$ Glasses System. Chem. Mater. 2000, 12, 30803088.

(6) Hench, L. L. Chronology of Bioactive Glass Development and Clinical Applications. New J. Glass Ceram. 2013, 03, 67-73.

(7) Vichery, C.; Nedelec, J.-M. Bioactive Glass Nanoparticles: From Synthesis to Materials Design for Biomedical Applications. Materials 2016, 9, 288.

(8) Lei, B.; Chen, X.; Han, X.; Zhou, J. Versatile fabrication of nanoscale sol-gel bioactive glass particles for efficient bone tissue regeneration. J. Mater. Chem. 2012, 22, 16906-16913.

(9) Mozafari, M.; Rabiee, M.; Azami, M.; Maleknia, S. Biomimetic formation of apatite on the surface of porous gelatin/bioactive glass nanocomposite scaffolds. Appl. Surf. Sci. 2010, 257, 1740-1749.

(10) Roohani-Esfahani, S. I.; Nouri-Khorasani, S.; Lu, Z. F.; Appleyard, R. C.; Zreiqat, H. Effects of bioactive glass nanoparticles on the mechanical and biological behavior of composite coated scaffolds. Acta Biomater. 2011, 7, 1307-1318.

(11) Ji, L.; Wang, W.; Jin, D.; Zhou, S.; Song, X. In vitro bioactivity and mechanical properties of bioactive glass nanoparticles/polycaprolactone composites. Mater. Sci. Eng. C 2015, 46, 1-9.

(12) Wang, C.; Shen, H.; Tian, Y.; Xie, Y.; Li, A.; Ji, L.; Niu, Z.; Wu, D.; Qiu, D. Bioactive Nanoparticle-Gelatin Composite Scaffold with Mechanical Performance Comparable to Cancellous Bones. ACS Appl. Mater. Interfaces 2014, 6, 13061-13068.

(13) Stöber, W.; Fink, A.; Bohn, E. Controlled growth of monodisperse silica spheres in the micron size range. J. Colloid Interface Sci. 1968, 26, 62-69.

(14) Lin, S.; Ionescu, C.; Pike, K. J.; Smith, M. E.; Jones, J. R. Nanostructure evolution and calcium distribution in sol-gel derived bioactive glass. J. Mater. Chem. 2009, 19, 1276-1282.

(15) Labbaf, S.; Tsigkou, O.; Müller, K. H.; Stevens, M. M.; Porter, A. E.; Jones, J. R. Spherical bioactive glass particles and their interaction with human mesenchymal stem cells in vitro. Biomaterials 2011, 32, 1010-1018.

(16) de Oliveira, A. A. R.; de Souza, D. A.; Dias, L. L. S.; de Carvalho, S. M.; Mansur, H. S.; de Magalhães Pereira, M. Synthesis, characterization and cytocompatibility of spherical bioactive glass nanoparticles for potential hard tissue engineering applications. Biomed. Mater. 2013, 8, 025011.

(17) Wu, C.; Fan, W.; Chang, J. Functional mesoporous bioactive glass nanospheres: synthesis, high loading efficiency, controllable delivery of doxorubicin and inhibitory effect on bone cancer cells. $J$. Mater. Chem. B 2013, 1, 2710-2718.

(18) Maeno, S.; Niki, Y.; Matsumoto, H.; Morioka, H.; Yatabe, T.; Funayama, A.; Toyama, Y.; Taguchi, T.; Tanaka, J. The effect of calcium ion concentration on osteoblast viability, proliferation and differentiation in monolayer and 3D culture. Biomaterials 2005, 26, 4847-4855.

(19) Marie, P. J. The calcium-sensing receptor in bone cells: A potential therapeutic target in osteoporosis. Bone 2010, 46, 571-576.

(20) Pereira, M. M.; Clark, A. E.; Hench, L. L. Effect of Texture on the Rate of Hydroxyapatite Formation on Gel-Silica Surface. J. Am. Ceram. Soc. 1995, 78, 2463-2468.

(21) Tsigkou, O.; Labbaf, S.; Stevens, M. M.; Porter, A. E.; Jones, J. R. Monodispersed Bioactive Glass Submicron Particles and Their Effect on Bone Marrow and Adipose Tissue-Derived Stem Cells. Adv. Healthc. Mater. 2013, 3, 115-125.

(22) Greasley, S. L.; Page, S. J.; Sirovica, S.; Chen, S.; Martin, R. A.; Riveiro, A.; Hanna, J. V.; Porter, A. E.; Jones, J. R. Controlling particle size in the Stöber process and incorporation of calcium. J. Colloid Interface Sci. 2016, 469, 213-223. 
(23) Zheng, K.; Taccardi, N.; Beltrán, A. M.; Sui, B.; Zhou, T.; Marthala, V. R. R.; Hartmann, M.; Boccaccini, A. R. Timing of calcium nitrate addition affects morphology, dispersity and composition of bioactive glass nanoparticles. RSC Adv. 2016, 6, 95101-95111.

(24) Hughes, J. M.; Budd, P. M.; Grieve, A.; Dutta, P.; Tiede, K.; Lewis, J. Highly monodisperse, lanthanide-containing polystyrene nanoparticles as potential standard reference materials for environmental "nano" fate analysis. J. Appl. Polym. Sci. 2015, 132, 42061.

(25) Jones, J. R. Reprint of: Review of bioactive glass: From Hench to hybrids. Acta Biomater. 2015, 23, S53-S82.

(26) Brinker, C. J.; Scherer, G. W. The Physics and Chemistry of SolGel Processing; Academic Press: Boston, 1990.

(27) Sepulveda, P.; Jones, J. R.; Hench, L. L. In vitro dissolution of melt-derived $45 S 5$ and sol-gel derived $58 \mathrm{~S}$ bioactive glasses. J. Biomed. Mater. Res. 2002, 61, 301-311.

(28) Zheng, K.; Dai, X.; Lu, M.; Hüser, N.; Taccardi, N.; Boccaccini, A. R. Synthesis of copper-containing bioactive glass nanoparticles using a modified Stöber method for biomedical applications. Colloids Surf., B 2017, 150, 159-167.

(29) Lukowiak, A.; Lao, J.; Lacroix, J.; Nedelec, J.-M. Bioactive glass nanoparticles obtained through sol-gel chemistry. Chem. Commun. 2013, 49, 6620-6622.

(30) Bell, N. C.; Minelli, C.; Tompkins, J.; Stevens, M. M.; Shard, A. G. Emerging Techniques for Submicrometer Particle Sizing Applied to Stöber Silica. Langmuir 2012, 28, 10860-10872.

(31) Zheng, K.; Boccaccini, A. R. Sol-gel processing of bioactive glass nanoparticles: A review. Adv. Colloid Interface Sci. 2017, 249, 363-373.

(32) Yu, B.; Turdean-Ionescu, C. A.; Martin, R. A.; Newport, R. J.; Hanna, J. V.; Smith, M. E.; Jones, J. R. Effect of Calcium Source on Structure and Properties of Sol-Gel Derived Bioactive Glasses. Langmuir 2012, 28, 17465-17476.

(33) Van Blaaderen, A.; Van Geest, J.; Vrij, A. Monodisperse colloidal silica spheres from tetraalkoxysilanes: particle formation and growth mechanism. J. Colloid Interface Sci. 1992, 154, 481-501.

(34) Kozon, D.; Zheng, K.; Boccardi, E.; Liu, Y.; Liverani, L.; Boccaccini, A. Synthesis of Monodispersed Ag-Doped Bioactive Glass Nanoparticles via Surface Modification. Materials 2016, 9, 225.

(35) El-Rashidy, A. A.; Waly, G.; Gad, A.; Hashem, A. A.; Balasubramanian, P.; Kaya, S.; Boccaccini, A. R.; Sami, I. Preparation and in vitro characterization of silver-doped bioactive glass nanoparticles fabricated using a sol-gel process and modified Stöber method. J. Non-Cryst. Solids 2018, 483, 26-36. 